\title{
1. Introduction, Part 1
}

The inevitable never happens. It is the unexpected always. J.M. Keynes

Alan Greenspan began a speech by saying that "Uncertainty is not just an important feature of the monetary policy landscape; it is the defining characteristic of that landscape" (2003, p. 1). He went on to say that "As a consequence, the conduct of monetary policy in the United States at its core involves crucial elements of risk management, a process that requires an understanding of the many sources of risk and uncertainty that policymakers face" (p. 1).

Fifteen years later at the same Jackson Hole venue, Federal Reserve Chair Jerome Powell $(2018$, p. 1) echoed Greenspan's view. Referring to the role of concepts like the natural rate of unemployment $\left(\mathrm{u}^{*}\right)$ and the neutral rate of interest $\left(\mathrm{r}^{*}\right)$, he stated "Guiding policy by the stars has been challenging of late because our best assessments of the location of the stars have changed significantly." He reiterated Greenspan's view of the need for a risk management strategy.

More than 20 years prior to Greenspan's speech, Paul Volcker, Greenspan's predecessor as Chairman of the Board of Governors, had announced a major Federal Reserve policy shift. Henry Wallich (1984), explaining that policy shift of October 1979, wrote that "Policymakers must take into account at all times the fact that both the economy and the demand for money may exhibit instability." It followed that "The optimum strategy depends on circumstances. Changing circumstances ... determine changes in strategy."

Greenspan articulated a flexible risk management approach to monetary policy. To critics who argued that such an approach was "too undisciplined - judgmental, seemingly discretionary, and difficult to explain" (p. 5), he responded that tying "policy to the prescriptions of a formal rule is unlikely to lead to an improvement in economic performance" (p. 5).

In the post-1980 period there was new momentum for monetary policy by commitment to a rule. Commitment to a form of inflation targeting was adopted by many central banks. As explained by an architect of the strategy, "Inflation targeting was expected to eliminate a potential source of macroeconomic instability, namely, the possibility of wage-price spirals triggered by commodity price shocks of the kind that had been problematic 
in the 1970s" (Woodford, 2012). Policy reacted to changing circumstances. In this case, to the importance of a new type of shock, the effects of which could not be offset completely. As a result, attention moved to preventing pass-through effects via inflationary expectations.

One difficulty with a formal rule that Greenspan had raised was that there were too many sources of instability to be encompassed by a feasible rule. With respect to a rule for inflation, the question was raised of whether such a rule should take account of asset as well as goods price inflation. Woodford (2003, p. 13) states that, "The answer provided by the theory developed here is no." The prices monetary policy should stabilize are those that are "sticky" while asset prices are among the most flexible and large fluctuations in them may be desirable if this makes more stability of the sticky prices possible. During the latter part of the Great Moderation a seeming broad consensus formed on the objectives of monetary policy, the model framework, the underlying optimal strategy, and its implementation. Inflation targeting ensures price stability and contributes to output stability. Macroeconomic stability can be achieved through adjustment of a sole policy instrument, the short-term interest rate. Managing inflationary expectations is fundamental to the success of monetary policy. Woodford (2003, p. 15) argues that "Not only do expectations about policy matter, but, at least under current conditions, very little else matters." Not even conditions in financial markets.

By 2007 circumstances had again changed. The years (1934-2007) that Gorton (2012) has termed the "Quiet Period" had come to an end. In the wake of the ensuing financial crisis and severe recession, one lesson taken was that stabilizing goods price inflation was not a sufficient condition for stability of the economy. Many policymakers and economists (not all) concluded that stabilizing the financial system should be a separate policy goal. The qualifier in the sentence coined by Woodford (2003) above matters. In post-financial crisis conditions, the analysis of how monetary policy should respond to shocks from the demand side and from financial markets - the shocks that occupied the literature in the 1970s and 1980s - is relevant.

Thus changes in the sources of uncertainty drove choices of monetary policy strategy, a relationship long recognized in the academic literature. The study of the nature of this relationship within formal stochastic macroeconomic models has been an active research area in the years since the publication of papers such as Brainard (1967) and Poole (1970). The issue Alan Greenspan raised about the role of formal rules versus more flexible frameworks such as what he terms a "risk-management paradigm" is likewise an area of longstanding interest in the academic literature. This book is a study of what has been learned from these lines of research.

Our survey of this literature on optimal monetary policy has three 
features. First, we emphasize the way in which optimal policy depends on information available to policymakers: what the policymaker is assumed to observe, at what point the observation is made, and with what accuracy it is made. In this literature different "optimal" policies across studies often result from varying assumptions about information sets. This is obvious only when information sets are explicitly compared. The information or signal extraction aspect of the optimal policy question has been subject to relative neglect in the literature of recent decades.

Second, we attempt to sort out the often confusing terminology in the optimal monetary policy literature. Benjamin Friedman (1975) pointed out that while "keeping one's eye on the ball is often an important precept in games of skill and games of chance" for monetary policy "a recurring problem has been the difficulty of determining what is the real ball." $\mathrm{He}$ was referring to confusion over concepts such as instruments, targets (ultimate or intermediate) and indicators for monetary policy. In the more recent literature we find, if not confusion, certainly complexity, for example with reference to policy rules. There are instrument rules that are implicit, explicit, simple, mechanical or forecast-based. Target rules are general, specific, simple, forecast-based or combinations of these types. We attempt to clarify and where possible simplify terminology to get at "the real ball."

Third, we take a long view, tracing the development of the literature on monetary policy under uncertainty back to the early contributions of Poole (1970) and Brainard (1967) among others. The literature at particular times reflects the concerns of that time often using models that ignore considerations not central to issues of the day. For example, many of the New Keynesian models considered in Part 2 of the book make unrealistic informational assumptions such as current observability of the output gap and inflation; the particular information sets available to policymakers were not the central concern. Many of these models have no financial sectors, just interest rate rules for policy. This seemed adequate and convenient for the question of control of inflation - the central concern of these models. When the 2007-09 financial crisis came, however, the models were unable to explain it or provide remedies. A return to older models that contained detailed treatments of financial markets and institutions was a required first step for development of a new generation of micro-based models. As the novelist William Faulkner observed, "The past is never dead. It is not even past."

The book is divided into three parts. In Part 1 (Chapters 2-6) optimal policy is considered within an aggregate supply and demand framework. Chapter 2 employs a fixed price version of this model to examine the instrument problem as considered by Poole (1970) and Brainard's (1967) contribution on optimal policy in the presence of multiplier uncertainty. Chapter 3 considers the role of intermediate targets and information vari- 
ables. Chapter 4 brings in the supply side and inflationary expectations. Chapter 5 extends the framework to the open economy. Chapter 6 surveys literature on the time inconsistency problem analyzed in Kydland and Prescott (1977) and Barro and Gordon (1983a), and for the open economy by Romer (1993). The chapter also considers later papers suggesting institutional arrangements that could improve central bank performance. These arrangements include delegation mechanisms analyzed by Rogoff (1985b) and Lohmann (1992), and performance contracts for central banks examined in Walsh (1993) and Waller (1995).

In Part 2, the focus shifts to an $I S$ schedule and Phillips Curve as the core of the closed economy framework. Chapter 7 introduces the new framework. Policy in this framework is represented by interest rate rules reflecting the current strategy of major central banks. Within this framework, often termed New Keynesian, there are different specifications of the Phillips Curve. In Chapter 8, we analyze the microeconomic foundations of these incarnations of the Phillips Curve: the Calvo (1983) model of sticky prices; Rotemberg's (1982) quadratic price adjustment model; the Taylor (1979, 1980) model of staggered wage contracts; and the Mankiw and Reis (2002) and Ball, Mankiw and Reis (2005) model of incomplete information.

Chapters 9-11 consider optimal monetary policy with a "forwardlooking" Phillips Curve specification. Policies conducted by target and instrument rules in the canonical New Keynesian model are considered and compared in Chapter 9. Chapter 10 presents extensions of the forwardlooking model. The timeless perspective to optimal monetary policy suggested by Woodford (1999b) is explained. Alternative frameworks which involve delegation to a policymaker who acts under discretion and pursues goals such as price level targeting, a speed-limit policy or average inflation targeting are considered as alternatives to policy under commitment. Chapter 11 analyzes optimal policy in an open-economy version of the forward-looking model.

Chapter 12 completes Part 2 with an analysis of the backward-looking Phillips Curve specification of the model considered by Ball (1999a, 1999b) and others. We look at optimal monetary policy issues in both an open and a closed-economy version of the model.

Part 3 surveys some of the post-crisis literature on monetary policy under uncertainty and topical issues in financial intermediation. One area where the pre-crisis framework was acknowledged to be deficient was in the treatment of financial institutions and markets. In the canonical New Keynesian model, which was central to monetary policy analysis in the two decades prior to the financial crisis, financial markets and institutions had been banished. Much of the literature we consider in Part 3 attempts to remedy this deficiency. 
Following a brief introduction (Chapter 13), the first chapter in the body of this part, Chapter 14, provides a retrospective look at the literature from the 1960s to the mid-1990s that developed a general equilibrium approach to financial institutions and financial markets. Keynesian and monetarist economists, including Gurley and Shaw, Brainard and Tobin, Ando and Modigliani, Brunner and Meltzer, stressed the interrelationships between financial and real factors in determining variables such as output and inflation. A literature also emerged that examined the role of "financial frictions" in the transmission mechanism for monetary policy. This older literature is a useful background for evaluating efforts to integrate financial factors into a newer generation of dynamic stochastic general equilibrium models. Also of interest are the reasons these considerations in the earlier literature were banished from mainstream frameworks for policy analysis.

Chapter 15 considers extensions of the canonical New Keynesian models. Examples are, models that incorporate financial frictions and heterogeneity among economic agents, models that consider unconventional monetary policy tools such as large asset purchases, and models that add additional policy goals such as financial stability. Considerations of financial stability bring us to the ongoing debate about the relative roles in central bank policy of macroprudential and traditional monetary policy objectives. The chapter also examines proposed alternatives to the New Keynesian framework. One example is the Brunnermeier-Sannikov (2012, 2014) framework where financial frictions and amplifying mechanisms with subsequent wealth effects assume the central role in the transmission of financial disturbances.

Part 3 concludes (Chapter 16) with consideration of a sample of recent work on banking and financial intermediation issues. Much of this literature reverts to partial equilibrium frameworks to explore issues such as a possible risk channel for monetary policy, excessive inside money creation in low interest rate environments and composition effects in company finance during economic downturns. 